conflicts of interest. ${ }^{2-5}$ Clinical research is dictated by the need to promote products of industry. In this sense, academics may have indeed lost control of the clinical research agenda. Many important questions in clinical research have no connections with specific products and thus would not be supported by industry. ${ }^{8}$ Such questions may never be funded or may not be cited frequently once published.

The recent increase in funding for profit may not be solely due to the need of industry to advertise. Recent cuts in government research budgets, together with the steady increase of applications for funding, provide an opening for the private sector. ${ }^{90}$ Trials sponsored by industry are more likely to show favourable outcomes, ${ }^{11}$ and be published in prestigious journals. Randomised controlled trials usually receive many citations, ${ }^{12}$ especially if they show "positive" results. Citations strengthen the prestige of the journal, and journals may wish to publish only those papers that are likely to be cited often, thereby creating a vicious circle.

\section{The future of academic medicine}

Our findings are in line with the scenario of "Academic Inc," with academic medicine evolving into an efficient enterprise that is directed by profit with strong ties to other profit making corporate structures. ${ }^{13}$ Our findings do not agree with a scenario where academic medicine disappears. Most influential research originates from the US and other wealthy countries, a situation that is dissonant with a global view of health needs. Government and the public sector still make major contributions to academic research, despite the rapid increase in industry sponsorship. Medical research should reflect public needs more closely.

NAP and AAA thank A Germenis for his encouragement. This work was conducted under the auspices of the International Campaign to Revitalise Academic Medicine (ICRAM) as part of the effort to evaluate the evidence base for academic medicine. Members of the ICRAM Working Party are listed on bmj.com/ academicmedicine.

Contributors: See bmj.com

Funding: None.

Competing interests: None declared.

\section{What is known on this topic}

Academics may be losing control of the research agenda and of clinical research at large

\section{What this study adds}

Most of the frequently cited papers on medical research in the past decade continue to have authors with academic affiliations

Since 1994, biotechnology and drug companies have provided funding to an increasing proportion of frequently cited studies

Industry funding has become ubiquitous for frequently cited randomised controlled trials, and most of these influential trials have no other sources of funding

Ethical approval: Not required.

1 Johns MM, Barnes M, Florencio PS. Restoring balance to industryacademia relationships in an era of institutional financial conflicts of interest: promoting research while maintaining trust. JAMA 2003; 289:741-6.

2 Ioannidis JP. Materializing research promises: opportunities, priorities and conflicts in translational medicine. J Transl Med 2004;2:5.

3 Bekelman JE, Li Y, Gross CP. Scope and impact of financial conflicts of interest in biomedical research: a systematic review. JAMA 2003;289: 454-65.

4 Boyd EA, Bero LA. Assessing faculty financial relationships with industry: a case study. JAMA 2000;284:2209-14.

5 AAMC Task Force on Financial Conflicts of Interest in Clinical Research. Protecting subjects, preserving trust, promoting progress II: principles and recommendations for oversight of an institution's financial interests in human subjects research. Acad Med 2003;78:237-45.

6 Garfield E. How can impact factors be improved? BMJ 1996;313:411-3.

7 Dickersin K, Scherer R, Suci ES, Gil-Montero M. Problems with indexing Dickersin K, Scherer R, Suci ES, Gil-Montero M. Problems with indexing
and citation of articles with group authorship. JAMA 2002;287:2772-4.

Egger M, Bartlett C, Juni P. Are randomised controlled trials in the BMJ different? BMJ 2001;323:1253-4.

Kaiser J. NIH funding. Success rates squeezed as budget growth slows. Science 2005;307:1023

10 Korn D, Rich RR, Garrison HH, Golub SH, Hendrix MJ, Heinig SJ, et al. Science policy. The NIH budget in the "postdoubling" era. Science 2002;296:1401-2.

11 Lexchin J, Bero LA, Djulbegovic B, Clark O. Pharmaceutical industry sponsorship and research outcome and quality: systematic review. BMJ 2003:326:1167-70.

12 Patsopoulos NA, Analatos AA, Ioannidis JP. Relative citation impact of various study designs in the health sciences. JAMA 2005;293:2362-6.

13 Awasthi S, Beardmore J, Clark J, Hadridge P, Madani H, Marusic A, et al. International Campaign to Revitalise Academic Medicine. Five futures for academic medicine. PLoS Med 2005;2:e207.

(Accepted 2 February 2006)

doi $10.1136 /$ bmj.38768.420139.80

\title{
Commentary: Is society losing control of the medical research agenda?
}

Brendan Delaney

Funding for medical research comes from three sources: government, charities, and industry. Research funded by industry should benefit the public, but as an aside to commercial interests. Patsopoulos et al compared the proportion of the most frequently cited articles in the Institute for Scientific Information database that were funded by public or industry sources over the past decade. ${ }^{1}$ They found a significant trend towards funding by industry, despite the continued dominance of academics as authors. If we take this as a robust finding, three questions arise: why is this happening; what are its implications; and what, if anything, should be done about it?
Clinical academic medicine has long had ties with industry-academics are funded to speak at conferences, provide consultancy, or help design and conduct studies. In many countries, academia is increasingly adopting a commercial approach, as universities seek alternative sources of income in response to declining public investment. The rise in the influence of industry may be as much pull as push, especially where science parks, commercial spin-offs, and intellectual property rights are concerned. However, this increasing

This article was posted on bmj.com on 17 March 2006: http://bmj.com/ cgi/doi/10.1136/bmj.38771.471563.80 


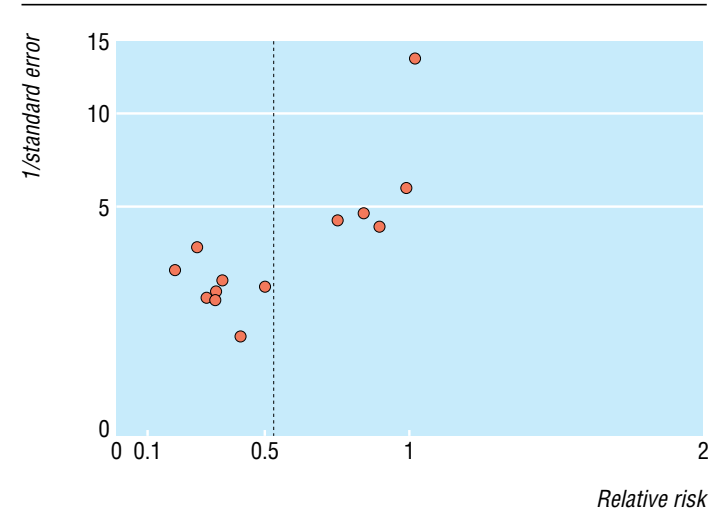

Funnel plot ${ }^{4}$ showing asymmetry in meta-analysis of randomised controlled trials of cisapride versus placebo in non-ulcer dyspepsia. If relative risk (effect size) is plotted against 1/standard error, small negative trials should balance small positive trials. This plot indicates an absence of negative trials, which biases the pooled effect.

"privatisation" of public life has implications for society as a whole.

The production of national guidelines that are both evidence based and cost effective may pitch society against the interests of industry. For example, most of the evidence on which the 2004 NICE (National Institute for Health and Clinical Excellence) guidelines on dyspepsia are based came from randomised controlled trials funded by industry. ${ }^{2}$ This created several distortions in the evidence base. Firstly, evidence from trials of proton pump inhibitors was abundant compared with data for off-patent treatments such as metoclopramide or lifestyle interventions. Secondly, placebo was chosen as a comparator when "current" treatment would have been better. Thirdly, in one instance (cisapride in non-ulcer dyspepsia) a large number of poor quality studies funded by industry led to a result that was later discounted as potentially biased (figure). ${ }^{3}$

The issues raised in the paper by Patsopoulos et al are pertinent to many areas of life, not just medicine. When she was Britain's prime minister, Margaret Thatcher said, "There is no such thing as society." Although we cannot ignore or shun industry, there is such a thing as civic society, and effective mechanisms are needed to protect its interests against those of private individuals and corporations. Absolute transparency of declaration of interests is one mechanism, and investment in detailed analysis of potential bias and evidence gaps in the production of guidelines is another. Public funding for research needs to concentrate on these gaps-for example, by comparing new drugs with cheaper and older ones and complex and behavioural interventions that cannot be patented. Industry should also be more transparent over trial registration and public access to data that affect patient care. A decline in public funding for high quality research is worrying and would ultimately harm patients. However, recent funding announcements in the United Kingdom indicate that government recognises this threat, and some correction of the balance should take place in the coming decade.

Competing interests: BD has been paid a speaker's honorarium and travel expenses by Astra-Zeneca, Wyeth, Reckitt Benkiser, AxCan Pharma, and Takeda; he has also been paid for advice on research by Astra-Zeneca, Wyeth, and Merck. He has received small project grants from Astra-Zeneca and Wyeth and major grants and fellowship funding from the NHS, Medical Research Council, and National Institutes of Health (USA). He is a part time principal general practitioner and part time academic funded by Higher Education Funding Council for England. He receives travel funding from Oxford University Press as editor of Family Practice. $\mathrm{He}$ is not a member of a political party. $\mathrm{He}$ coauthored the technical report for the National Institute for Health and Clinical Excellence 2004 dyspepsia guideline.

1 Patsopoulos NA, Analatos AA, Ioannidis JPA. Origin and funding of the most frequently cited papers in medicine: database analysis. $B M$ 2006;332:1061-3

National Institute of Health and Clinical Excellence. The management of dyspepsia in adult patients in primary care. London, UK: NICE, 2004.

Soo S, Moayyedi P, Deeks J, Delaney B, Harris A, Innes M, Bennett C, Forman F. Pharmalogical interventions for non-ulcer dypepia (full Cons Cochrane review). In: The Cochrane Library. Oxford: Update Software,

4 Sterne JAC, Egger M, Smith GD. Investigating and dealing with publication and other biases in meta-analysis. BMJ 2001;323:101-5 .

5 Douglas K. Margaret Thatcher interviewed in “Woman's Oun”, 23 Sep 1987. www.margaretthatcher.org/speeches/ displaydocument.asp?docid = 106689 (accessed 9 Feb 2006).

6 Department of Health. Best research for best health. London: DOH, 2006. www.dh.gov.uk/PublicationsAndStatistics/Publications/

PublicationsPolicyAndGuidance

PublicationsPolicyAndGuidanceArticle/fs

en?CONTENT ID $=4127127 \&$ chk $=$ uSh6qN $($ accessed 9 Feb 2006)

(Accepted 20 February 2006)

doi $10.1136 /$ bmj. 38771.471563 .80
Editorial by

Panagiotakos and Pitsavos

Deep South Center on Effectiveness Research,

Birmingham

Veterans Affairs

Medical Center,

Birmingham, AI

USA

Thomas K Houston assistant professor of

medicine

Catarina I Kiefe professor of medicine

continued over

BMJ 2006;332:1064-7

\section{Active and passive smoking and development of glucose intolerance among young adults in a prospective cohort: CARDIA study}

Thomas K Houston, Sharina D Person, Mark J Pletcher, Kiang Liu, Carlos Iribarren, Catarina I Kiefe

\begin{abstract}
Objective To assess whether active and passive smokers are more likely than non-smokers to develop clinically relevant glucose intolerance or diabetes. Design Coronary artery risk development in young adults (CARDIA) is a prospective cohort study begun in 1985-6 with 15 years of follow-up.
\end{abstract}

Setting Participants recruited from Birmingham, Alabama; Chicago, Illinois; Minneapolis, Minnesota; and Oakland, California, USA.

This is the abridged version of an article that was posted on bmi.com on 7 April 2006: http://bmi.com/cgi/doi/10.1136/ bmj.38779.584028.55 